\title{
Genetic and genomic approaches to the detection of heart transplant rejection
}

Since Christiaan Barnard performed the first heart transplant in 1967, over 100,000 heart transplants have been performed worldwide. As was true then, rejection remains the major threat to the function and survival of the allograft. The development of the endomyocardial biopsy as a means to monitor for rejection has allowed heart transplantation to thrive as a therapy for patients with end-stage heart disease. The need for a noninvasive method of rejection surveillance led to the development of the first genetic test for allograft rejection, the AlloMap ${ }^{\circledR}$. In this article, after presenting the pathological and clinical features of cardiac allograft rejection, the authors discuss the development and application of geneexpression testing for the detection of cardiac allograft rejection. We then explore emerging 'omic' approaches that will be the rejection detection methods of the future.

\section{KEYWORDS: antibody-mediated rejection cellular rejection endomyocardial biopsy gene-expression profiling genomics heart transplantation mycophenolate mofetil pharmacogenomics tacrolimus}

Heart transplantation is the therapy of choice for patients with end-stage heart failure. For patients who survive the first year after transplant, the median survival is 14 years [1]. Heart transplant recipients experience an excellent quality of life, and have climbed mountains and completed triathlons $[2,3]$. Behind these successes is the reality that recipients must adhere to a life-long regimen of immunosuppressive therapy to maintain their immune system in a state of quiescence. By contrast, when the recipient's immune system is active and attacks the cardiac allograft, rejection occurs. With improvements in immunosuppressive therapies, the incidence of rejection requiring hospitalization has decreased from $59 \%$ of all patients by 5 years after transplant (for patients receiving transplants between April 1994 and 2000) to $44 \%$ (for patients receiving transplants between 2001 and June 2009) (FIgURe 1) [1]. Despite this improvement, rejection remains the most important cause of allograft dysfunction and death in the early period after transplant.

Although immunosuppressant therapies have decreased rejection, they contribute to major complications that limit longevity after transplantation: infection, renal failure and cancer. Thus, the ability to tailor each patient's level of immunosuppression to their risk of rejection would decrease these consequences [4]. The extant clinical risk factors for rejection are not adequate to identify which patients will develop rejection. As a result, surveillance for rejection via serial endomyocardial biopsy (EMB) has been a standard part of post-transplant care since the early days of heart transplantation [5]. The need for a noninvasive test led to the development and validation of gene-expression profiling (GEP) as a powerful methodology for stratifying a patients' risk of post-transplant rejection.

In this article, the authors present the past, present and future of detection of cardiac allograft rejection. First the authors review the timing, risk factors and grading of cardiac allograft rejection, as determined by pathological analysis of endomyocardial biopsies. Next, the development and validation of GEP as a clinically important test to aid in the monitoring and diagnosis of rejection is discussed. Preliminary data from other genetic and genomic approaches, such as candidate gene-association studies of cytokine and drug metabolism genes, are then presented. Finally, the authors examine ongoing research into other 'omic approaches to the detection of rejection that will be the detection methods of the future.

\section{An overview of cardiac allograft rejection}

The process of heart transplantation, which is limited by the availability of donor organs and the need to minimize organ ischemic time, leads to mismatch between the donor organ and recipient within the MHC. Located on chromosome six, the MHC contains the class I and II gene clusters that produce HLA, which

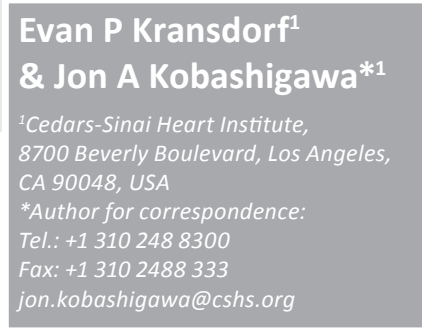

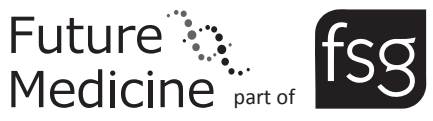




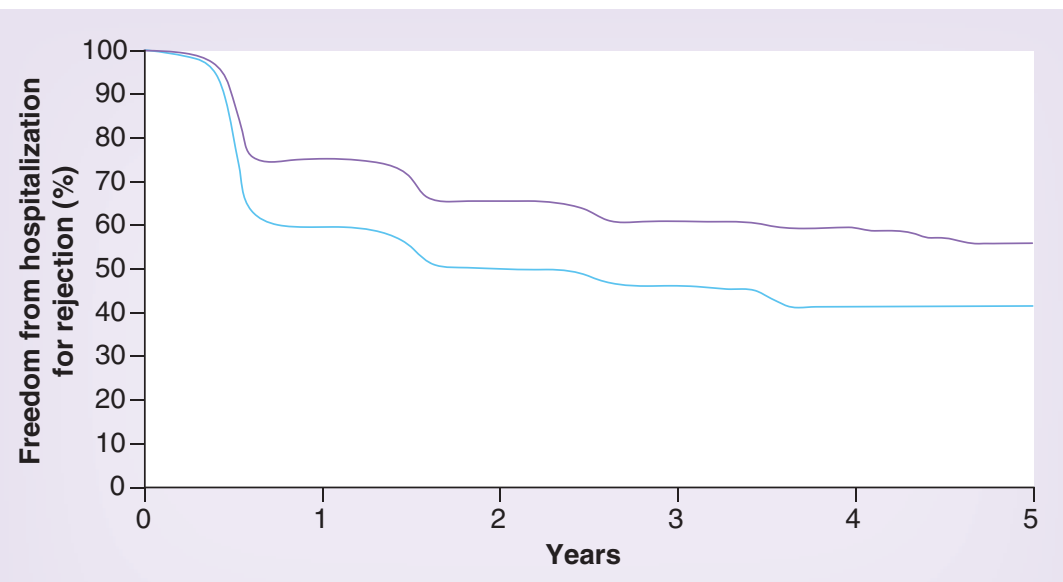

- Freedom from hospitalization for rejection January 2001-June 2009 ( $n=6331)$ Freedom from hospitalization for rejection April 1994-December $2000(n=4890)$

Figure 1. The frequency of hospitalization for the treatment of cardiac allograft rejection has decreased. The purple line represents the years April 1994-December 2000, in which $59 \%$ of all patients were free of hospitalization by 5 years. The blue line represents the years January 2001-June 2009, in which 44\% of all patients were free of hospitalization by 5 years.

Reproduced with permission from [1] moderate) or greater is treated by augmentation of immunosuppression.

AMR was recognized as pathologically distinct from CR over 20 years ago, but its incidence and importance have increased as $\mathrm{CR}$ rates have declined and more patients with circulating anti-HLA antibodies undergo transplantation $[18,19]$. This form of rejection is most common in the first year after transplantation, occurring in approximately $6.5 \%$ of patients $[20,21]$. AMR occurs when antibodies against HLA antigens, present either before or formed after transplant, bind to the allograft and activate complement, leading to tissue injury. The pathological criteria for AMR include both a histological and immunological component (TABLE 1 \& Figure 3) [22] Histologically, AMR manifests as endothelial cell activation, intravascular macrophage accumulation and interstitial edema. Capillary deposition of complement fragments $\mathrm{C} 3 \mathrm{~d}$ or $\mathrm{C} 4 \mathrm{~d}$ is also usually present.

The clinical manifestations of both CR and AMR vary from none (no apparent changes in allograft function by echocardiography or cardiac catheterization), to symptomatic heart failure, to severe hemodynamic compromise. Overall, the short-term outcome for patients with symptomatic CR, even with high-grade rejection, is good [23]. However, patients experiencing CR within the first year after transplant tend to develop coronary allograft vasculopathy with higher frequency and at an earlier time than those without CR [20,24]. By contrast, CR with hemodynamic compromise, often requiring inotropes or mechanical circulatory support, only occurs in between 4 and $6 \%$ of patients by the end of the first year post-transplant, but is associated with a high mortality ( $40 \%$ by 1 year) $[9,25]$. When symptomatic AMR occurs, it is more frequently associated with allograft dysfunction and hemodynamic compromise than CR [26]. Even when AMR is asymptomatic, it is also associated with a higher frequency of cardiac allograft vasculopathy development [27]. [10-12]. The characteristics of recipients at highe risk for CR include: younger age; female gender; and African-American race [7,13].

Mechanistically, CR is due to direct and indirect allorecognition, which lead to T-cell activation and infiltration of the allograft [14]. Histopathology shows infiltration of lymphocytes and macrophages, with the grade of rejection corresponding to the extent of tissue affected and the presence of myocyte damage (Table 1 \& Figure 3) [15]. In general, rejection of grade $1 \mathrm{R}$ (low or mild) is not treated, as it remains lowgrade or resolves spontaneously $80 \%$ of the time $[16,17]$. Rejection of grade $2 \mathrm{R}$ (intermediate or

\section{GEP (transcriptomics) for detection of CR}

Despite the known risk factors for CR, it is not possible to predict which patients will develop $\mathrm{CR}$ and at what time point after transplant. Given the significant morbidity and mortality associated with CR and AMR, all transplant programs perform rejection surveillance by routine EMB after transplant. The duration of surveillance varies among programs, with some programs stopping at 1 year post-transplant, and 
Table 1. Pathological criteria for the grading of cellular and antibody-mediated rejection.

\begin{tabular}{|lll|}
\hline $\begin{array}{l}\text { Type of rejection } \\
\text { Cellular }\end{array}$ & Grade & Pathological findings \\
& OR & $\begin{array}{l}\text { None } \\
\text { Interstitial and/or perivascular infiltrate, with up to one focus of myocyte } \\
\text { damage }\end{array}$ \\
& $2 \mathrm{R}$ & $\begin{array}{l}\text { Two or more foci of infiltrate with associated myocyte damage } \\
\text { Diffuse cellular infiltrate with multifocal myocyte damage with or without } \\
\text { edema, hemorrhage and vasculitis }\end{array}$ \\
& $3 \mathrm{R}$ & None \\
Antibody mediated & 0 & Histology or immunopathology positive \\
& 1 & Histology and immunopathology positive \\
& 2 & Interstitial hemorrhage, capillary fragmentation and marked edema \\
& 3 &
\end{tabular}

others continuing beyond 10 years [28,29]. EMB is considered to be the 'gold-standard' method for the diagnosis of rejection; however, it has a number of important limitations. First, EMB is an invasive test and as such causes patient discomfort and can cause complications such as pericardial effusion, tricuspid regurgitation and fistula formation [29,30]. Next, the test requires an experienced operator and catheterization laboratory time, which is resource intensive [31]. Furthermore, the interpretation of the histological grade of rejection is variable, with two recent studies showing only fair agreement between expert pathologists ( $\kappa$ value of 0.4 ) $[32,33]$. Other diagnostic methodologies for CR, such as echocardiography [34] and cardiac magnetic resonance imaging [35] have not achieved wide-spread use.

Given the limitations of EMB, GEP has been developed as an alternative and noninvasive test for rejection. The value of GEP for the detection of CR was first demonstrated by Schoels and colleagues [36], who demonstrated that expression levels of five immune-related genes (measured at the time of EMB) could distinguish between rejection (grade $2 \mathrm{R}$ and above) and quiescence (grade 0 or $1 \mathrm{R}$ ). Horwitz was then the first to use complementary DNA (cDNA) microarrays on patient samples in an effort to correlate histological rejection, detected by EMB, with the peripheral blood gene-expression profile [37]. They collected peripheral blood samples at the time of EMB from seven patients with CR and seven patients with no CR (control samples). The patients with rejection were treated, and post-rejection samples were also collected. RNA was isolated from the blood samples, which was then reverse transcribed into cDNA. cDNA was hybridized to Affymetrix U133a microarrays (Affymetrix, CA, USA). This analysis identified seven genes that were upregulated, and 84 genes that were downregulated. There was high reproducibility between samples (coefficient of variation 4\%). Using a hierarchical clustering method, these genes were paired down to 30 unique transcripts that best distinguished between rejection, control and post-rejection samples. This study was 'proof-of-principle' that the peripheral blood gene expression profile could be used to identify histologic cardiac allograft rejection.

The next major step in the development of a noninvasive test for rejection was the multicenter CARGO study [38]. This study was designed to test the hypothesis that a GEP test, performed

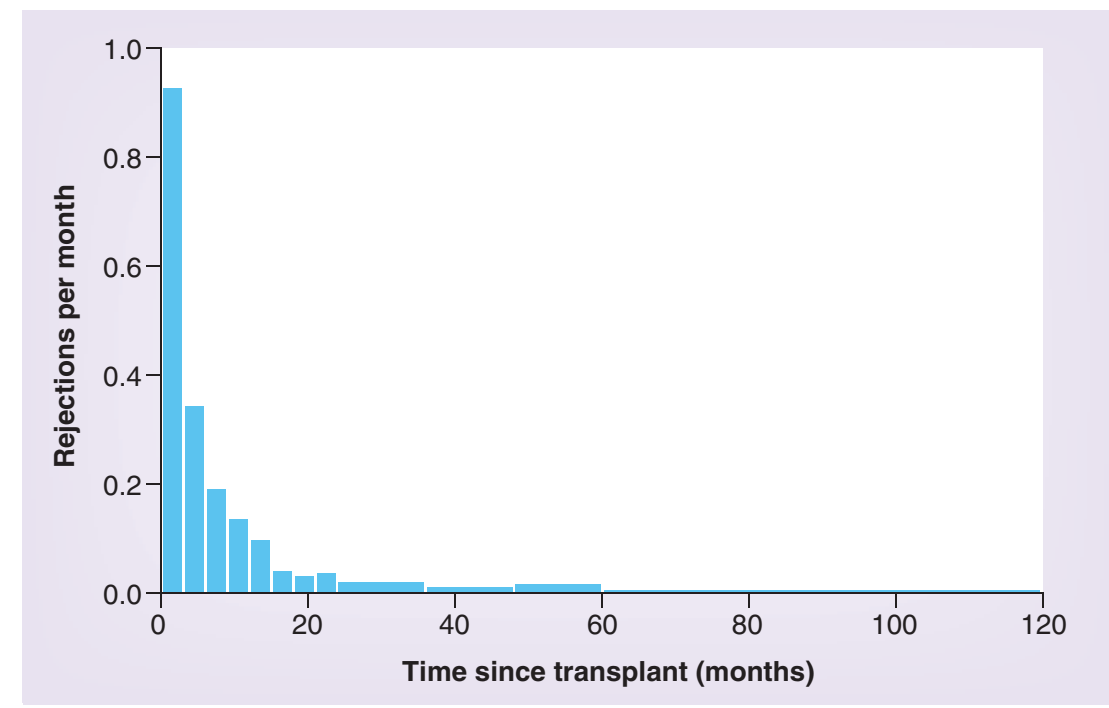

Figure 2. The incidence of cellular rejection is highest in the first year post-transplant and then declines to a low, but constant level.

Reproduced with permission from [12]. 

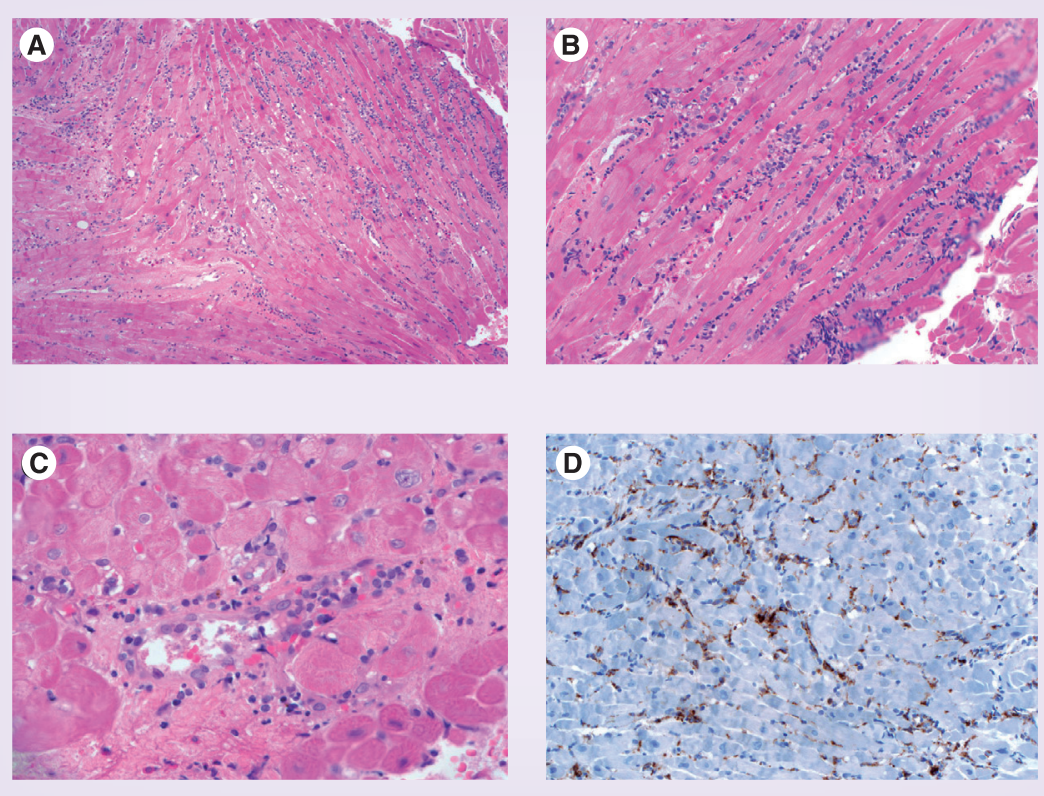

Figure 3. Photomicrographs of endomyocardial biopsy samples showing cellular rejection and antibody-mediated rejection. (A) Myocardium with lymphocytic infiltrate consistent with intermediate or moderate (grade 2R) cellular rejection (100x magnification). (B) Higher magnification (200x). (C) Capillary with activated endothelial cells and intravascular macrophages consistent with antibodymediated rejection (400x). (D) Immunoperoxidase staining positive for CD68 highlighting intravascular macrophages (brown) in antibody-mediated rejection (200x).

Images courtesy of Dan Luthringer, Cedars-Sinai Medical Center (CA, USA).

using RNA extracted from peripheral blood mononuclear cells, could discriminate significant allograft rejection (grade $2 \mathrm{R}$ and above) from allograft quiescence (no rejection). The CARGO study had three phases: candidate gene discovery; assay development; and assay validation. In the candidate gene discovery phase, 247 samples from 94 patients with rejection grade $2 \mathrm{R}$ or above and 38 samples from 28 patients without rejection were hybridized to custom-made microarrays. Using several statistical techniques including statistical analysis of microarrays and hierarchical clustering, a set of 97 candidate genes was identified. An additional 155 genes were identified by correlated expression, related function or literature review of genes involved in rejection, for a total of 252 candidate genes.

In the assay development phase, real-time PCR assays were performed on each of the 252 candidate genes, using 109 samples from 86 patients with rejection, and 36 samples from 28 patients with quiescence. Ultimately, 62 genes were identified that distinguished rejection from quiescence. Importantly, four pathologists reviewed each sample to ensure consensus on the histological grade of the sample. A linear discriminant analysis was performed to identify the genes that provided the best discrimination of rejection and quiescence. The final equation used the expression levels of 11 genes to give an expression score between 0 and 40 (Table 2). This type of assay, where multiple markers are integrated to yield a single score, is called an In vitro diagnostic multivariate index assay. Lower scores indicate quiescence and higher scores suggest that the immune system is active, and in a small number of cases $C R$ will be present.

A validation study was then performed using a set of 62 samples from 50 patients with rejection and 122 samples from 83 patients with quiescence. Using a threshold score of 28 to discriminate quiescence from rejection at any time point, the test had a sensitivity of $75.8 \%$, and a specificity of $41.8 \%$. On further analysis, an increase in the mean GEP score was associated with increasing time from transplant. This increased score was later correlated to lower corticosteroid dose and weaning [39]. The steroid sensitivity of the GEP is not surprising, given that three genes in the score are steroid sensitive. By using a higher threshold score of 30 , applied to samples obtained greater than 12 months post-transplant, the performance of the test improved to a sensitivity of $80.0 \%$, and a specificity of $77.8 \%$.

This GEP test, known commercially as the AlloMap ${ }^{\circledR}$ Molecular Expression Test (XDx, CA, USA), became available for clinical use in January 2005. The Working Group on Molecular Testing in Cardiac Transplantation published their initial clinical experience with the AlloMap in 2006 [40]. First, they showed that in a 'real-world' population greater than 1-year post-transplant, using a threshold score of 34 increased the sensitivity of the test to $100 \%$, while maintaining the specificity at $71.3 \%$. Thus, the AlloMap could effectively rule out rejection in this population. They recommended that the AlloMap could be used to evaluate for $\mathrm{CR}$ in adult patients at low risk of rejection, who were greater than 2 months post-transplant. They recommended that the AlloMap not be used for certain patients at high risk of CR or with conditions that might interfere with the assay (Box 1).

Although the initial clinical results with the AlloMap were encouraging, Pham and colleagues developed a clinical trial to more fully evaluate patient outcomes using the AlloMap as the primary means of CR surveillance [41]. In the IMAGE trial, adult patients between 6-months and 5-years post-transplant were randomized to a 
Table 2. Characterization of the 11 genes that compose the AlloMap ${ }^{\oplus}$ score. $^{\circ}$

\begin{tabular}{|c|c|c|c|}
\hline AlloMap genes & $\begin{array}{l}\text { Expression } \\
\text { change in ACR }\end{array}$ & $\begin{array}{l}\text { Source of expression in } \\
\text { blood }\end{array}$ & $\begin{array}{l}\text { Role in immune } \\
\text { activation and } \\
\text { rejection }\end{array}$ \\
\hline $\begin{array}{l}\text { ITGAM, FLT3 and } \\
\text { ILIR2 }\end{array}$ & Decreased & Monocytes & Steroid response \\
\hline PF4 and C6ORF25 & Decreased & Platelets & Platelet activation \\
\hline $\begin{array}{l}\text { WDR } 40 A \text { and } \\
\text { MARCH8 }\end{array}$ & Increased & Reticulocytes & $\begin{array}{l}\text { Proliferation and } \\
\text { mobilization of } \\
\text { erythrocytes }\end{array}$ \\
\hline $\mathrm{RHOU}$ & Increased & T cells and monocytes & Unknown \\
\hline PDCD1 & Increased & T cells & T-cell priming \\
\hline ITGA4 & Increased & T cells & T-cell priming \\
\hline SEMA7A & Increased & $\begin{array}{l}\text { T cells, B cells and } \\
\text { neutrophils }\end{array}$ & Unknown \\
\hline
\end{tabular}

surveillance protocol using primarily AlloMap or EMB, at intervals determined by center-specific protocol [42]. Exclusion criteria included severe cardiac allograft vasculopathy, AMR and symptomatic heart failure. A total of 602 patients were randomized, with 297 assigned to the GEP group and 305 assigned to the EMB group. Patients were followed for the primary outcome, the first occurrence of rejection with hemodynamic compromise, graft dysfunction due to nonrejection causes, death or retransplantation, for a maximum of 24 months. In the GEP arm, a threshold score of $\geq 34$ triggered a biopsy to evaluate for CR. Other events triggering a biopsy were symptoms or signs of allograft dysfunction, or a decrease of the allograft ejection fraction by $\geq 25 \%$ from baseline.

The IMAGE trial found that over a median follow-up duration of 19 months, the 2 year rate of the primary composite outcome was statistically similar in the GEP and EMB groups, with composite event rates of 14.5 and $15.3 \%$, respectively (Table 3). This result was independent of the time post-transplant and the transplantation center. The GEP group had $67 \%$ fewer biopsies (409 in the GEP group versus 1249 in the EMB group). Numerically, there were a higher number of treated rejection episodes in the biopsy group than the GEP group (34 or $11.8 \%$ in the GEP group vs 47 or $16.0 \%$ in the EMB group). Given that there was a similar rate of adverse events in each group, a small number of CR events are not detected by the AlloMap, but are clinically insignificant. Thus, the IMAGE trial demonstrated that a CR surveillance strategy using the AlloMap, when used with standard clinical assessment and echocardiography, reduced the number of biopsies without a statistically significant difference in outcomes.

Although very promising, there are a number of limitations of the IMAGE trial that merit discussion. First, $85 \%$ of the patients in the IMAGE trial were between 1 and 5 years post-transplant, when the overall risk of rejection is low (approximately $0.1-0.2$ episodes per patient in years $1-3)[28,43]$. Indeed, only six of the 274 biopsies performed for an elevated GEP were associated with an episode of treated rejection. Given this data, the high negative predictive value, as well as the low positive predictive value, of the test could have been due to the overall low incidence of rejection in this population. Next, there is concern that the low rate of the primary outcome led to wide confidence intervals that statistically demonstrate noninferiority of the AlloMap strategy, but not equivalence, of the two strategies [44].

A critical question is whether the AlloMap is sufficiently sensitive to detect rejection in

Box 1. Clinical contraindications to the use of the AlloMap ${ }^{\circledR}$ for cellular

rejection monitoring.

- Cardiac allograft dysfunction

- Hemodynamic rejection in last 6 months

- Antibody-mediated rejection in last 12 months

- Pregnancy

- Blood transfusion in last 30 days

- Hematopoietic growth factors in last 30 days

- Patient less than 15 years of age

- High-dose steroids in last 21 days

- Daily prednisone administration >20 mg 


\section{Table 3. Results of the IMAGE study.}

\begin{tabular}{|c|c|c|}
\hline & $\begin{array}{l}\text { GEP } \\
\text { group }\end{array}$ & $\begin{array}{l}\text { Biopsy } \\
\text { group }\end{array}$ \\
\hline Primary outcome (2-year rate; \%) & 14.5 & 15.3 \\
\hline Deaths (2-year rate; \%) & 6.3 & 5.5 \\
\hline Indication for biopsies ( $\mathrm{n})$ : & 409 & 1249 \\
\hline - Routine per center protocol & NA & 1125 \\
\hline - Performed for elevated GEP & 274 & NA \\
\hline - Clinically driven biopsies & 70 & 31 \\
\hline - Performed within 90 days of treatment for rejection & 52 & 58 \\
\hline - Off-protocol biopsies & 13 & 35 \\
\hline Treated rejection episodes $(n)$ : & 34 & 47 \\
\hline - Grade $O R$ and $1 R$ & 10 & 13 \\
\hline - Grade $2 R$ and $3 R$ & 13 & 25 \\
\hline - Mixed and AMR & 11 & 9 \\
\hline \multicolumn{3}{|l|}{ Clinical presentation of rejection $(n)$ : } \\
\hline - Asymptomatic & NA & 22 \\
\hline - Clinical rejection and/or allograft dysfunction by echo & 20 & 25 \\
\hline - Clinical rejection and elevated GEP score & 14 & NA \\
\hline - Elevated GEP score & 6 & NA \\
\hline \multicolumn{3}{|c|}{$\begin{array}{l}\text { 'Clinically driven' biopsies were performed for clinical symptoms and signs of allograft failure or for } \\
\text { allograft dysfunction (dysfunction as defined by a decrease in the ejection fraction of } \geq 25 \% \\
\text { compared with first visit value). } \\
\text { OR: None; } 1 R \text { : Low or mild; } 2 R \text { : Intermediate or moderate; } 3 R \text { : High or severe; AMR: Antibody- } \\
\text { mediated rejection; Echo: Echocardiography; GEP: Gene-expression profiling: NA: Not applicable. } \\
\text { Data taken from [42]. }\end{array}$} \\
\hline
\end{tabular}

patients in the 'high-risk' period for CR, the first 6 months after transplant. To address this question, our center is currently conducting the EIMAGE trial [101]. In this trial, heart transplant patients $\geq 55$ days, but less than 185 days, post-transplant were randomized to rejection surveillance via EMB versus AlloMap with clinical assessment and echocardiography. The primary composite outcome is similar to that of the original IMAGE trial, with the addition of first year intravascular ultrasound to measure coronary artery intimal medial thickness. The trial has completed enrollment and is ongoing.

A further criticism of the AlloMap is that there is no mechanistic evidence (e.g., from mouse models) that the gene expression profile of mononuclear cells in the peripheral blood corresponds to the gene expression profile of T cells in the allograft (the principle effectors of CR). However, several clinical studies, in addition to the previously discussed CARGO study, support the clinical validity of this strategy. Lin and colleagues used Affymetrix U133 microarrays to identity a 12-gene panel that differentiated between patients with rejection and quiescence with a sensitivity of $83 \%$ and a specificity of
$100 \%$ [45]. Furthermore, Hollander and colleagues performed microarray-based GEP on endomyocardial and whole-blood samples from 11 patients with rejection (grade $2 \mathrm{R}$ and above) and 20 patients in quiescence (grade $0 \mathrm{R}$ [none]) [46]. They identified 1169 genes that were differentially expressed between rejection and quiescence in both endomyocardium and whole blood. Taken together, these results suggest that despite the current lack of mechanistic evidence, GEP performed using peripheral blood mononuclear cells can detect immunologic activation within the allograft and the risk of CR. The final genes selected identify the best independent performers associated with pathology-confirmed rejection.

\section{Methods for detection of AMR}

AMR affects fewer patients than CR after transplant, and is more prevalent in patients with circulating anti-HLA antibodies. First identified in kidney transplantation, the development of AMR can be anticipated in patients with donorspecific anti-HLA antibodies $[47,48]$. Solid-phase antibody assays using single-antigen beads are the most sensitive method to detect these antibodies [49]. Cadeiras and colleagues were able to identify a gene-expression profile that correlated with AMR using samples from the CARGO study [50]. However, AlloMap scores have not been shown to correlate with AMR. Because the AlloMap was designed to detect CR which is a mechanistically distinct process, there is no role for the AlloMap in monitoring for AMR.

Recently, a novel method for monitoring complement-fixing anti-HLA antibodies, named the $\mathrm{Clq}$ assay, has been introduced into clinical practice [51]. It has previously been shown that the circulating anti-HLA antibodies that lead to AMR require complement fixation to cause tissue injury [52]. However, only a small subset of circulating anti-HLA antibodies fix complement. In the C1q assay, after a patient's serum is bound to single-antigen HLA-beads, a labeled antibody against the first component of the classical complement pathway, $\mathrm{Clq}$, is added to the reaction. The amount of labeled anti-Clq antibody is then determined, along with the HLA-specificity of the bead. Chin and colleagues recently published their experience with the C1q assay in 18 sensitized pediatric heart transplant recipients [47]. They found that a positive C1q assay after transplant correlated with the development of AMR (positive and negative predictive values of $100 \%)$. Although clinical experience with the C1q assay is still limited, the preliminary clinical 
data suggest that it is a very promising technique for the noninvasive prediction of AMR.

\section{Genetic \& genomic approaches to predicting the risk of $C R$}

Since the publication of the first complete human genome sequence in 2001, a major goal of genomic research has been to catalog and characterize the genomic variation between individuals. This variation takes two main forms: SNPs and structural variants. A SNP is a variation in the DNA sequence at a single nucleotide position, present in at least $1 \%$ of the population (Figure 4). Structural variants lead to changes in the size of the genome and can be insertions, deletions, copy number variations or inversions (Figure 4). Recent data suggest that approximately $0.1 \%$ of the genome is composed of SNPs and approximately $1 \%$ of the genome is composed of structural variants [53,54].

The last 10 years have seen the publication of more than a 1000 studies linking SNPs to complex diseases such as heart failure and hypertension [55,56]. The primary methods for identifying SNPs associated with diseases are genome-wide association studies and candidate gene association studies (CGAS). As yet, there are no published genome-wide association studies in solid-organ transplantation, although the Wellcome Trust is currently conducting a study to determine the role of genetics in early and late renal transplant dysfunction [102]. In heart transplantation, several investigators have performed CGAS to identify SNPs associated with rejection. In these studies, SNPs in the promoter or coding region of a gene of functional importance are genotyped in cases (patients with rejection) and controls (patients without rejection). The effects of the SNPs on the gene's expression are usually known a priori. The extant CGAS studies in heart transplantation have focused on two main areas: cytokine genes and drug metabolism genes (also known as pharmacogenomics).

Cytokines are critical components of the immune response to the cardiac allograft and have also been shown to mediate the ventricular dysfunction of CR [57,58]. Multiple studies have linked polymorphisms in cytokine genes to rejection in heart transplantation (reviewed by Girnita and colleagues [59]). In one of the first studies to examine this association, Turner and colleagues found that patients with a $\mathrm{G}>\mathrm{A}$ polymorphism (at position 308) in the TNF- $\alpha$ gene promoter and a G $>$ A polymorphism (at position 1082) in the IL-10 gene promoter had a statistically higher incidence of early CR [60]. These SNPs were also found to be associated with an increased risk of CR, both alone and in combination, in a study of 93 pediatric heart transplant recipients, whereas SNPs in the IFN- $\gamma$, IL- 6 , and TGF- $\beta$ genes had no effect [6]. In vitro data suggest that the above TNF- $\alpha$ and IL-10 SNPs lead to altered levels of gene transcription, which lead to an increased inflammatory response in vivo [62,63].

A limitation of the candidate gene approach to SNP identification in transplantation is that there is inconsistency between studies. For example, in a multicenter study of 323 pediatric transplant recipients, Girnita and colleagues found that the above-mentioned SNPs in the TNF- $\alpha$ and IL-10 genes were not independently associated with an increased risk of rejection [64]. However, a $\mathrm{G}>\mathrm{C}$ polymorphism (at position 174) in the $I L-6$ gene promoter in combination with the IL-10 SNP was associated with an increased risk of CR. They also identified three SNPs in the VEGF gene that, in combination with the IL-6 and/or the IL-10 SNP, were associated with an increased risk of CR.

Recently, Benza and colleagues found that a $\mathrm{G}>\mathrm{C}$ polymorphism in the coding region of the TGF- $\beta$ gene was associated with the risk of CR [65]. Patients with the high-risk 'GG' genotype had a mean of two treated rejections during the first year post-transplant, compared with 1.25 for patients with the low-risk 'CC' or 'GC' genotypes. This association remained statistically significant in a multivariable model considering other clinical risk factors associated with rejection. Although these results are highly encouraging, laboratory methods for the identification

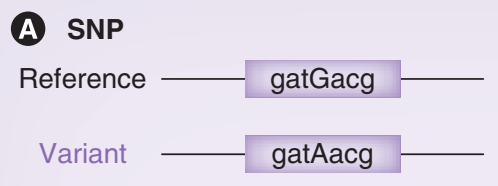

\section{B Structural variants}

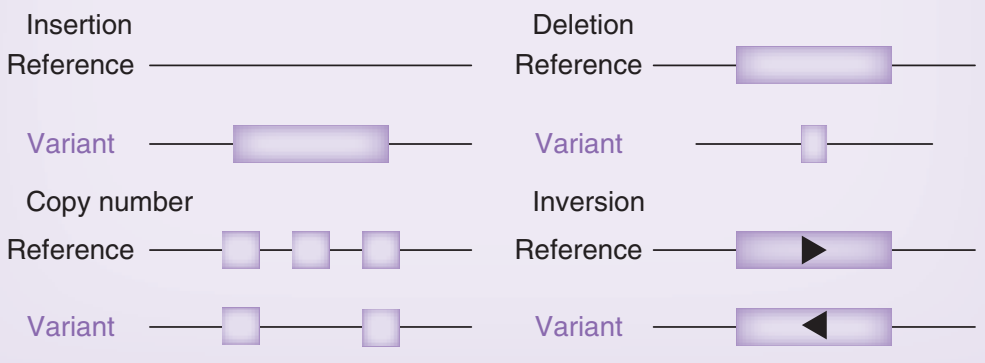

Figure 4. Types of variation in the genome. (A) SNPs are differences at a single nucleotide position. (B) Structural variations come in several forms, such as insertions, deletions, copy number variations and inversions, which lead to a change in the size of the overall genome. 
of cytokine gene SNPs are not widely available and the combination of SNPs with the best diagnostic criteria have not yet been identified.

Tacrolimus (tac), cyclosporine (csa) and mycophenolate mofetil (MMF) are the most widely used immunosuppressant agents in heart transplantation [1]. Recent pharmacogenomic studies, which correlate SNPs in the genes for the enzymes which metabolize these agents to clinical outcomes, have recently yielded important insights into their toxicities [66]. In particular, csa and tac can contribute to advanced chronic kidney disease, which affects $10 \%$ of patients by 5 years post-transplant and is associated with an increased mortality. de Denus and colleagues performed a CGAS for SNPs in the CYP3A5 and $A B C B 1$ genes, which encode the CYP450 isoenzyme 3A5 and P-glycoprotein, in 160 heart transplant recipients [67]. They found that the $C Y P 3 A 5^{*} 1$ polymorphism was associated with a higher estimated glomerular filtration rate at all points post-transplant for patients treated with csa or tac. This association was independent of other predictors of renal function. By contrast, no such association was found for the $A B C B 1$ SNPs. As shown in Figure 5, the $C Y P 3 A 5^{*} 3$ genotype, which is the wild-type, leads to a splice mutation in the gene that leads to an absence of functional protein, which in turn probably leads to higher levels of toxic tac metabolites [68].

Polymorphisms in the CYP3A5 gene have also been found to correlate with tac dose requirements. Recent data from the DeKAF study shows that patients with the $C Y P 3 A 5^{*} 1$ polymorphism have lower tac trough levels $36 \%$ lower for one ${ }^{*} 1$ allele and $59 \%$ lower for two ${ }^{*} 1$ alleles), despite higher tac doses [69]. The association of CYP3A5 polymorphisms with tac dosing has been confirmed in adult and pediatric heart transplant recipients [70,71]. Interestingly, the $C Y P 3 A 5^{*} 1$ polymorphism is present in $65 \%$ of African-Americans, compared with $8 \%$ of non-African-Americans. This polymorphism explains why most African-American patients require higher doses of tac to achieve therapeutic trough levels, which in turn may contribute to the increased risk of allograft rejection observed in African-American patients.

The side-effects of MMF therapy, such as diarrhea and leukopenia, are common and lead to dose reduction or even discontinuation of therapy in approximately $15 \%$ of treated patients [9]. The metabolism of MMF is more complex than tac, involving conjugation of its active metabolite mycophenolic acid in the liver by glucuronosyltransferases and enterohepatic circulation via MRP-2 [66]. mycophenolic acid inhibits the enzyme IMPDH, which ultimately results in inhibition of $\mathrm{T}$ - and $\mathrm{B}$-cell proliferation [72]. Ohmann and colleagues performed a CGAS for SNPs in the ABCC2, IMPDH1 and $I M P D H 2$ genes, which encode the MRP-2 protein and the two isoforms of IMPDH, in 59 pediatric heart transplant recipients [73]. No SNPs were statistically associated with bonemarrow toxicity. However, a $\mathrm{G}>\mathrm{A}$ polymorphism (at position 14338) in intron 7 and a $>A$ polymorphism (at position 20,408) in exon 15 were associated with a statistically higher rate of holding or discontinuing MMF for gastrointestinal intolerance.

Owing to their larger size and higher complexity, structural variants such as insertions and deletions are more difficult to link to a particular disease state. Copy number variation is more straightforward to assess, as the regions of variation are large $(>1 \mathrm{~kb})$ and as such, copy number can be detected with quantitative PCR. Copy number variation has recently been shown to have a role in the risk of rejection in nonheart solid organ transplant recipients. Colobran and colleagues reported that lung transplant recipients with $\geq 2$ copies of the chemokine CCL4L were more likely to experience acute rejection, with an odds ratio of 2.65, compared with patients with 0 or 1 copy [74]. Similarly, Li and colleagues found that liver transplant recipients with $\geq 3$ copies of the related chemokine CCL3L1 were more likely to experience acute rejection, with an odds ratio of 3.85, compared with patients with $<3$ copies [75]. Given these results, copy number variation may have an important role in CR; however, studies applying copy number variation analysis to heart transplant recipients are needed.

\section{Future molecular approaches for prediction \& detection of CR}

With recent advances in biotechnology, we are now able to investigate the relationship between the recipient and allograft at an unprecedented number of levels: genomic; epigenomic; transcriptomic; proteomic; metabolomic; immunophenotypic; and antibodyomic (Tarle 4). This collection of biologic information, as applied and integrated to understand transplantation, has been coined 'transplantomics' [76]. Previously, the authors discussed transcriptomic, genetic and genomic approaches to the detection of cardiac allograft rejection. Here the application of epigenomic, proteomic and antibodyomic approaches to the detection of allograft 
rejection are presented. These techniques have not yet been applied to heart transplantation, so we present three examples of their use in kidney transplantation.

Epigenetic phenomena are biological processes that cause heritable changes in gene expression without affecting the sequence of the gene itself. Several epigenetic phenomena are known to exist in humans: DNA methylation; histone coding; and RNAi. RNAi affects gene transcription through the production of short ncRNA sequences (usually 20-24 nucleotides in length) known as miRNA, that are now known to play a major role in the regulation of gene transcription and translation [77]. Given their pervasive role, Anglicheau and colleagues investigated whether there were differences in miRNA expression in renal allografts with rejection compared with those in quiescence [78]. First, they isolated miRNA from seven renal allograft biopsies, four normal and three with rejection, and applied these samples to an Applied Biosystems (CA, USA) miRNA microarray containing $365 \mathrm{miR}$ NAs. They identified 17 miRNAs that were differentially expressed at statistically significant levels. Next, the differential expression of six previously identified miRNAs was validated using real-time PCR assays on a 'validation set' of 26 renal allograft biopsies, 17 normal and nine with rejection. Interestingly, they identified three miRNAs (miR-142-5p, miR-155 and miR-223), which were each able to differentiate between rejection and quiescence with a sensitivity and specificity of greater than $90 \%$. Given these exciting results, miRNA GEP is

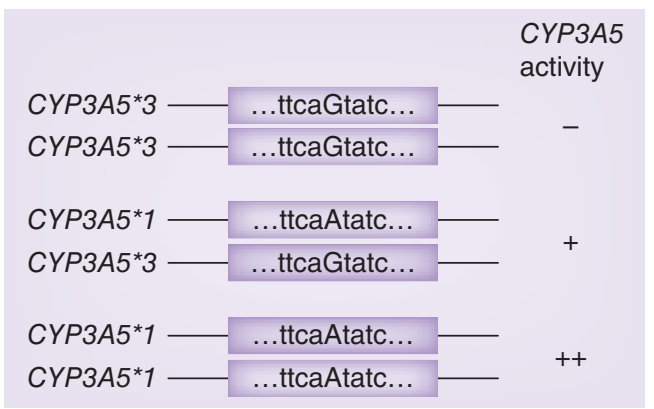

Figure 5. The CYPBA5 gene, showing the relationship between the CYP $3 A 5 * 1$ and *3 SNPs and gene expression.

another new method that may be useful for the detection of CR.

Proteomics is the identification and characterization of all the proteins that are produced by a given cell or tissue [79]. Freue and colleagues performed an extensive proteomic analysis on serum samples from 11 patients with early kidney rejection and 21 controls without rejection [80]. They identified 12 proteins that were increased and five proteins that were decreased in rejection samples as compared with controls. A classifier using three proteins was able to distinguish cases from controls. This study suggests that further application of serum proteomic analysis in heart transplantation may help identify new serum biomarkers for allograft rejection.

In AMR, circulating antibodies are usually directed against HLA antigens; however, in a minority of cases antibodies can also be detected against non-HLA proteins such as MHC class

\begin{tabular}{|c|c|c|}
\hline Level & Definition & Methods \\
\hline Genome & $\begin{array}{l}\text { The complete set of genetic information within a } \\
\text { cell or tissue }\end{array}$ & Next-generation genomic DNA sequencing \\
\hline Epigenome & $\begin{array}{l}\text { The complete set of nucleic acid modifications that } \\
\text { alter gene transcription, including DNA } \\
\text { methylation, histone coding and RNAi (miRNA) }\end{array}$ & $\begin{array}{l}\text { Bisulfite sequencing, chromatin } \\
\text { immunoprecipitation sequencing and miRNA arrays }\end{array}$ \\
\hline Transcriptome & $\begin{array}{l}\text { The complete set of gene transcripts (RNA) made } \\
\text { by a cell or tissue }\end{array}$ & $\begin{array}{l}\text { CDNA microarrays, real-time PCR and CDNA library } \\
\text { sequencing }\end{array}$ \\
\hline Proteome & $\begin{array}{l}\text { The complete set of proteins produced by a cell or } \\
\text { tissue }\end{array}$ & MuDPIT or DiGE followed by mass spectrometry \\
\hline Metabolome & $\begin{array}{l}\text { The complete set of metabolites produced by a cell } \\
\text { or tissue }\end{array}$ & Solute identification by mass spectrometry \\
\hline Immunophenotype & Comprehensive map of all immune cell phenotypes & Cell sorting \\
\hline Antibodyome & $\begin{array}{l}\text { The complete set of antibodies produced by a } \\
\text { patient }\end{array}$ & Protein arrays \\
\hline
\end{tabular}


I MICA and angiotensin type 1 receptor [81,82]. Identifying the targets of these non-HLA antibodies has been challenging. $\mathrm{Li}$ and colleagues published a promising new approach using 'antibodyomics,' in which a serum sample is applied to a protein array containing approximately 5000 human proteins [83]. Using paired preand post-kidney transplant samples, they found that de novo antibodies were produced against an average of $61 \%$ of the proteins on the array. To determine which antibodies were produced in response to the allograft, they compared the antibody responses against gene-expression data from seven kidney compartments. They found that genes expressed in the renal pelvis were the most strongly targeted in 14 out of 18 transplant recipients. The authors concluded that perioperative factors such as ischemia-reperfusion injury may expose this anatomic compartment, leading to a robust humoral immune response.

\section{Future perspective}

Although the incidence of cardiac allograft rejection has decreased over the last 10 years, it remains an important cause of morbidity and mortality after heart transplantation. As such,

\section{Executive summary}

\section{Heart transplantation}

- Heart transplantation is the therapy of choice for patients with end-stage heart failure, as it is associated with an excellent quality of life and survival.

- Because HLA matching between donor and recipient is not possible, patients are at risk for rejection after transplant, despite treatment with immunosuppressive medications such as tacrolimus and mycophenolate mofetil.

\section{Cardiac allograft rejection}

- The two major types of allograft rejection are cellular rejection (CR) and antibody-mediated rejection (AMR). Both forms of rejection are most common in the first post-transplant year. The incidence of $C R$ is decreasing with better immunosuppressive agents, while the incidence of AMR is increasing.

- The effect of rejection on allograft function varies from negligible to severe hemodynamic compromise requiring mechanical circulatory support.

- Extant clinical risk factors for a higher risk of cellular and AMR, such as younger age, female gender, African-American race and circulating anti-HLA antibodies, are not sufficient to identify the time point at which patients will develop rejection. Given this, all transplant programs perform rejection surveillance by routine endomyocardial biopsy (EMB).

\section{Gene-expression profiling for detection of $C R$}

- The potential for procedural complications and high resource requirements of EMB led to efforts to find a noninvasive test for cardiac allograft rejection.

- In the CARGO study, Deng and colleagues developed a gene-expression profiling assay that utilizes the expression levels of 11 genes in the blood to yield an expression score. Higher scores correlate with a higher risk of CR by EMB. This assay is known commercially as the AlloMap ${ }^{\circledR}$.

" In heart transplant patients greater than 1 year post-transplant, an AlloMap score of 34 or above suggests the possibility of rejection, while lower scores rule out the possibility of rejection.

- The use of the AlloMap for monitoring low-risk patients for cardiac allograft rejection was validated in the IMAGE trial. This trial showed that over a median follow-up of 19 months, the event rate of patients monitored by AlloMap and EMB was similar at 14.5 and $15.3 \%$, respectively.

- Because the majority of patients in the IMAGE trial were greater than 1 year post-transplant and the assay cannot detect AMR, the AlloMap has not replaced the EMB for patients at high risk of rejection (patients early post-transplant or with symptoms of rejection). The ongoing EIMAGE study will examine whether the AlloMap is sufficiently sensitive to detect rejection in patients early post-transplant.

\section{Genetic \& genomic approaches to predicting the risk of $C R$}

- Several studies have identified SNPs in the genes for the cytokines TNF- $\alpha$, IL-10, IL- 6 and TGF- $\beta$, which confer an increased risk for CR. Further identification of a predictive set of SNPS as well as prospective validation is needed before these markers can be used clinically.

" A SNP in the CYP3A5 gene, which leads to increased levels of the CYP3A5 enzyme which metabolizes tacrolimus, has been found to correlate with better renal function after heart transplant. This SNP is more common in African-Americans, and explains why these patients require higher levels of tacrolimus to achieve therapeutic trough levels.

\section{Future molecular approaches for prediction and detection of $\mathrm{CR}$}

- Technological advancements have made it possible to investigate the relationship between the recipient and allograft at multiple levels: genomic; epigenomic; transcriptomic; proteomic; metabolomic; and antibodyomic.

- With the application of these techniques to heart transplantation, we expect that in the next 5-10 years multimarker assays will be developed that can determine a patients risk of cellular and AMR. The clinician will use this information to individualize the patient's immunosuppressive regimen. 
the development and validation of the AlloMap GEP test was an important step towards the realization of genetic and genomic approaches to the detection of heart transplant rejection. Over the next 5-10 years, we anticipate that further characterization of the full spectrum of human genetic variation will lead to the development of multimarker assays (and potentially multitechnology assays, e.g., genomic and epigenomic) that can determine a patient's risk of cellular and AMR, as well as predict the development of toxicities in response to available immunosuppressive regimens. Using these data, the clinician will be able to individualize the patient's immunosuppressive agents and intensity. Further integration of the multiple levels of biologic information will be needed to realize this goal. We look forward to a time when transplant recipients, who have already suffered with end-stage organ failure, can enjoy a new lifetime with their allograft.

\section{Financial \& competing interests disclosure}

$J A$ Kobashigawa has received honoraria and/or research grants from XDX Inc. and Novartis Pharmaceuticals Inc. The authors have no other relevant affiliations or financial involvement with any organization or entity with a financial interest in or financial conflict with the subject matter or materials discussed in the manuscript apart from those disclosed.

No writing assistance was utilized in the production of this manuscript.

\section{References}

Papers of special note have been highlighted as:

- of interest

"I" of considerable interest

1 Stehlik J, Edwards LB, Kucheryavaya AY et al. The registry of the international society for heart and lung transplantation: twenty-eighth adult heart transplant report - 2011. J. Heart Lung Transplant. 30(10), 1078-1094 (2011).

- The 2011 report from the Transplant Registry of the International Society for Heart and Lung Transplantation provides a thorough discussion of the current management and outcomes after heart transplantation.

2 Kapp C. Heart transplant recipient climbs the Matterhorn. Lancet 362(9387), 880-881 (2003).

3 Haykowsky MJ, Riess K, Burton I, Jones L, Tymchak W. Heart transplant recipient completes ironman triathlon 22 years after surgery. J. Heart Lung Transplant. 28(4), 415 (2009).

4 Sprangers B, Kuypers DR, Vanrenterghem Y. Immunosuppression: does one regimen fit all? Transplantation 92(3), 251-261 (2011).

5 Caves PK, Stinson EB, Billingham ME, Rider AK, Shumway NE. Diagnosis of human cardiac allograft rejection by serial cardiac biopsy. J. Thorac. Cardiovasc. Surg. 66(3), 461-466 (1973).

6 Shiina T, Hosomichi K, Inoko H, Kulski JK. The HLA genomic loci map: expression, interaction, diversity and disease. J. Hum. Genet. 54(1), 15-39 (2009).

7 Jarcho J, Naftel DC, Shroyer TW et al. Influence of HLA mismatch on rejection after heart transplantation: a multiinstitutional study. The Cardiac Transplant Research
Database Group. J. Heart Lung Transplant. 13(4), 583-595; discussion 595-596 (1994).

8 Kaczmarek I, Deutsch MA, Rohrer ME et al. HLA-DR matching improves survival after heart transplantation: is it time to change allocation policies? J. Heart Lung Transplant. 25(9), 1057-1062 (2006).

9 Kobashigawa JA, Miller LW, Russell SD et al. Tacrolimus with mycophenolate mofetil (MMF) or sirolimus vs. cyclosporine with MMF in cardiac transplant patients: 1-year report. Am. J. Transplant. 6(6), 1377-1386 (2006).

10 Kirklin JK, Naftel DC, Bourge RC et al. Rejection after cardiac transplantation. A time-related risk factor analysis. Circulation 86(5 Suppl.), II236-II241 (1992).

11 Lietz K, John R, Kocher A et al. Increased prevalence of autoimmune phenomena and greater risk for alloreactivity in female heart transplant recipients. Circulation 104(90001), I177-I183 (2001).

12 Stoica SC, Cafferty F, Pauriah M et al. The cumulative effect of acute rejection on development of cardiac allograft vasculopathy. J. Heart Lung Transplant. 25(4), 420-425 (2006).

13 Kobashigawa JA, Kirklin JK, Naftel DC et al. Pretransplantation risk factors for acute rejection after heart transplantation: a multiinstitutional study. The Transplant Cardiologists Research Database Group. J. Heart Lung Transplant. 12(3), 355-366 (1993).

- Part of the body of work that details the timing and risk factors for cellular rejection.

14 Wood KJ, Goto R. Mechanisms of rejection: current perspectives. Transplantation 93(1), 1-10 (2012).

15 Stewart S, Winters GL, Fishbein MC et al. Revision of the 1990 working formulation for the standardization of nomenclature in the diagnosis of heart rejection. J. Heart Lung Transplant. 24(11), 1710-1720 (2005).

16 Brunner-La Rocca HP, Sütsch G, Schneider J, Follath F, Kiowski W. Natural course of moderate cardiac allograft rejection (International Society for Heart Transplantation grade 2) early and late after transplantation. Circulation 94(6), 1334-1338 (1996).

17 Milano A, Caforio AL, Livi U et al. Evolution of focal moderate (International Society for Heart and Lung Transplantation grade 2) rejection of the cardiac allograft. J. Heart Lung Transplant. 15(5), 456-460 (1996).

18 Hammond EH, Yowell RL, Nunoda S et al. Vascular (humoral) rejection in heart transplantation: pathologic observations and clinical implications. J. Heart Transplant. 8(6), 430-443 (1989).

19 Kobashigawa J, Crespo-Leiro MG, Ensminger SM et al. Report from a consensus conference on antibody-mediated rejection in heart transplantation. J. Heart Lung Transplant. 30(3), 252-269 (2011).

20 Tadwalkar R, Patel J, Kittleson M, Czer L, Kobashigawa J. Consequences of first-year rejection after heart transplantation: is the worst yet to come? J. Am. Coll. Cardiol. 59(13), e992 (2012).

21 Kfoury AG, Snow GL, Budge D et al. A longitudinal study of the course of asymptomatic antibody-mediated rejection in heart transplantation. J. Heart Lung Transplant. 31(1), 46-51 (2012).

22 Berry GJ, Angelini A, Burke MM et al. The ISHLT working formulation for pathologic diagnosis of antibody-mediated rejection in heart transplantation: evolution and current status (2005-2011). J. Heart Lung Transplant. 30(6), 601-611 (2011). 
23 Mills RM, Naftel DC, Kirklin JK et al. Heart transplant rejection with hemodynamic compromise: a multiinstitutional study of the role of endomyocardial cellular infiltrate. Cardiac Transplant Research Database. J. Heart Lung Transplant. 16(8), 813-821 (1997).

24 Raichlin E, Edwards BS, Kremers WKet al. Acute cellular rejection and the subsequent development of allograft vasculopathy after cardiac transplantation. J. Heart Lung Transplant. 28(4), 320-327 (2009).

25 Haddad F, Fisher P, Pham M et al. Right ventricular dysfunction predicts poor outcome following hemodynamically compromising rejection. J. Heart Lung Transplant. 28(4), 312-319 (2009).

26 Michaels PJ, Espejo ML, Kobashigawa J et al. Humoral rejection in cardiac transplantation: risk factors, hemodynamic consequences and relationship to transplant coronary artery disease. J. Heart Lung Transplant. 22(1), 58-69 (2003).

27 Wu GW, Kobashigawa JA, Fishbein MC et al. Asymptomatic antibody-mediated rejection after heart transplantation predicts poor outcomes. J. Heart Lung Transplant. 28(5), 417-422 (2009).

28 Stehlik J, Starling R, Movsesian M et al. Utility of long-term surveillance endomyocardial biopsy: a multi-institutional analysis. J. Heart Lung Transplant. 25(12), 1402-1409 (2006).

29 Hamour IM, Burke MM, Bell AD, Panicker MG, Banerjee R, Banner NR. Limited utility of endomyocardial biopsy in the first year after heart transplantation. Transplantation 85(7), 969-974 (2008).

30 Saraiva F, Matos V, Gonçalves L, Antunes M, Providência LA. Complications of endomyocardial biopsy in heart transplant patients: a retrospective study of 2117 consecutive procedures. Transplant. Proc. 43(5), 1908-1912 (2011).

31 Evans RW, Williams GE, Baron HM et al. The economic implications of noninvasive molecular testing for cardiac allograft rejection. Am. J. Transplant. 5(6), 1553-1558 (2005).

32 Yang HM, Lai CK, Gjertson DW et al. Has the 2004 revision of the International Society of Heart and Lung Transplantation grading system improved the reproducibility of the diagnosis and grading of cardiac transplant rejection? Cardiovascular Pathology. 18(4), 198-204 (2009).

33 Angelini A, Andersen CB, Bartoloni G et al. A web-based pilot study of inter-pathologist reproducibility using the ISHLT 2004 working formulation for biopsy diagnosis of cardiac allograft rejection: the European experience. J. Heart Lung Transplant. 30 (11), 1214-1220 (2011).
34 Eleid MF, Caracciolo G, Cho EJ et al. Natural history of left ventricular mechanics in transplanted hearts. JACC Cardiovasc. Imaging 3(10), 989-1000 (2010).

35 Butler CR, Thompson R, Haykowsky M, Toma M, Paterson I. Cardiovascular magnetic resonance in the diagnosis of acute heart transplant rejection: a review. J. Cardiovasc. Magn. Reson. 11(1), 7 (2009).

36 Schoels M, Dengler T, Richter R, Meuer S, Giese T. Detection of cardiac allograft rejection by real-time PCR analysis of circulating mononuclear cells. Clin. Transplant. 18(5), 513-517 (2004).

37 Horwitz PA. Detection of cardiac allograft rejection and response to immunosuppressive therapy with peripheral blood gene expression. Circulation 110(25), 3815-3821 (2004).

38 Deng MC, Eisen HJ, Mehra MR et al. Noninvasive discrimination of rejection in cardiac allograft recipients using gene expression profiling. Am. J. Transplant. 6(1), 150-160 (2006).

"- Details the development of the AlloMap ${ }^{\circledR}$ for the detection of cardiac allograft rejection.

39 Starling R, Deng M, Kobashigawa J, Wohlgemuth J, Rosenberg S, Mehra M The influence of corticosteroids on the alloimmune molecular signature for cardiac allograft rejection. J. Heart Lung Transplant. 24(2), S65-S66 (2005).

40 Starling RC, Pham M, Valantine $\mathrm{H}$ et al. Molecular testing in the management of cardiac transplant recipients: initial clinical experience. J. Heart Lung Transplant. 25(12), 1389-1395 (2006).

41 Pham MX, Deng MC, Kfoury AG, Teuteberg JJ, Starling RC, Valantine H. Molecular testing for long-term rejection surveillance in heart transplant recipients: design of the Invasive Monitoring Attenuation Through Gene Expression (IMAGE) trial. J. Heart Lung Transplant. 26(8), 808-814 (2007).

- This IMAGE study validated that a cellular rejection surveillance strategy using the AlloMap was not associated with a statistically significant difference in outcomes, compared with the endomyocardial biopsy.

42 Pham MX, Teuteberg JJ, Kfoury AG et al. Gene-expression profiling for rejection surveillance after cardiac transplantation. N. Engl. J. Med. 362(20), 1890-1900 (2010).

43 Kubo SH, Naftel DC, Mills RM et al. Risk factors for late recurrent rejection after heart transplantation: a multiinstitutional, multivariable analysis. Cardiac Transplant Research Database Group. J. Heart Lung Transplant. 14(3), 409-418 (1995).
44 Mehra MR, Parameshwar J. Gene expression profiling and cardiac allograft rejection monitoring: is IMAGE just a mirage? J. Heart Lung Transplant. 29(6), 599-602 (2010).

45 Lin D, Hollander Z, Ng RT et al. Whole blood genomic biomarkers of acute cardiac allograft rejection. J. Heart Lung Transplant. 28(9), 927-935 (2009).

46 Hollander Z, Lin D, Chen V et al. Whole blood biomarkers of acute cardiac allograft rejection: double-crossing the biopsy. Transplantation 90 (12), 1388-1393 (2010).

47 Chin C, Chen G, Sequeria F et al. Clinical usefulness of a novel C1q assay to detect immunoglobulin $\mathrm{G}$ antibodies capable of fixing complement in sensitized pediatric heart transplant patients. J. Heart Lung Transplant. 30(2), 158-163 (2011).

48 Hodges AM, Lyster $\mathrm{H}, \mathrm{McDermott} \mathrm{A}$ et al. Late antibody-mediated rejection after heart transplantation following the development of de novo donor-specific human leukocyte antigen antibody. Transplantation 93(6), 650-656 (2012).

49 Fuggle SV, Martin S. Tools for human leukocyte antigen antibody detection and their application to transplanting sensitized patients. Transplantation 86(3), 384-390 (2008).

50 Cadeiras M, Bayern M, Burke E et al. Gene expression profiles of patients with antibodymediated rejection after cardiac transplantation. J. Heart Lung Transplant. 27(8), 932-934 (2008).

51 Yabu JM, Higgins JP, Chen G, Sequeira F, Busque S, Tyan DB. C1q-fixing human leukocyte antigen antibodies are specific for predicting transplant glomerulopathy and late graft failure after kidney transplantation. Transplantation 91(3), 342-347 (2011).

52 Rahimi S, Qian Z, Layton J, Fox-Talbot K, Baldwin WM, Wasowska BA. Noncomplement- and complement-activating antibodies synergize to cause rejection of cardiac allografts. Am. J. Transplant. 4(3), 326-334 (2004).

531000 Genomes Project Consortium. A map of human genome variation from populationscale sequencing. Nature 467(7319), 1061-1073 (2010).

54 Pang AW, MacDonald JR, Pinto D et al. Towards a comprehensive structural variation map of an individual human genome. Genome Biol. 11(5), R52 (2010).

55 Smith NL, Felix JF, Morrison AC et al. Association of genome-wide variation with the risk of incident heart failure in adults of European and African ancestry: a prospective meta-analysis from the cohorts for heart and aging research in genomic epidemiology (CHARGE) consortium. Circ. Cardiovasc. Genet. 3(3), 256-266 (2010). 
56 Ehret GB, Munroe PB, Rice KM et al.; International Consortium for Blood Pressure Genome-Wide Association Studies. Genetic variants in novel pathways influence blood pressure and cardiovascular disease risk. Nature 478(7367), 103-109 (2011).

57 Abbas AK, Lichtman AH, Pillai S. Cytokines. In: Cellular and Molecular Immunology (6th Edition). Saunders/Elsevier, Philadelphia, PA, USA, 267-302 (2011).

58 Barry WH. Mechanisms of immunemediated myocyte injury. Circulation 89(5), 2421-2432 (1994).

59 Girnita DM, Webber SA, Zeevi A. Clinical impact of cytokine and growth factor genetic polymorphisms in thoracic organ transplantation. Clin Lab Med. 28(3), 423-440 (2008).

" Details the extant data on the relationship between SNPs and outcome in thoracic transplantation.

60 Turner D, Grant SC, Yonan N et al. Cytokine gene polymorphism and heart transplant rejection. Transplantation 64(5), 776-779 (1997).

61 Awad MR, Webber S, Boyle G et al. The effect of cytokine gene polymorphisms on pediatric heart allograft outcome. J. Heart Lung Transplant. 20(6), 625-630 (2001).

62 Wilson AG, Symons JA, McDowell TL, McDevitt HO, Duff GW. Effects of a polymorphism in the human tumor necrosis factor alpha promoter on transcriptional activation. Proc. Natl Acad. Sci. USA 94(7), 3195-3199 (1997).

63 Turner DM, Williams DM, Sankaran D, Lazarus M, Sinnott PJ, Hutchinson IV. An investigation of polymorphism in the interleukin-10 gene promoter. Eur. J. Immunogenet. 24(1), 1-8 (1997).

64 Girnita DM, Brooks MM, Webber SA et al. Genetic polymorphisms impact the risk of acute rejection in pediatric heart transplantation: a multi-institutional study. Transplantation 85(11), 1632-1639 (2008).

65 Benza RL, Coffey CS, Pekarek DM et al. Transforming growth factor-beta polymorphisms and cardiac allograft rejection. J. Heart Lung Transplant. 28(10), 1057-1062 (2009).

66 Cattaneo D, Baldelli S, Perico N. Pharmacogenetics of immunosuppressants: progress, pitfalls and promises. Am. J. Transplant. 8(7), 1374-1383 (2008).

67 de Denus S, Zakrzewski M, Barhdadi A et al. Association between renal function and CYP3A5 genotype in heart transplant recipients treated with calcineurin inhibitors. J. Heart Lung Transplant. 30 (3), 326-331 (2011).

68 Lee SJ, Usmani KA, Chanas B et al. Genetic findings and functional studies of human CYP3A5 single nucleotide polymorphisms in different ethnic groups. Pharmacogenetics 13(8), 461-472 (2003).

69 Jacobson PA, Oetting WS, Brearley AM et al. Novel polymorphisms associated with tacrolimus trough concentrations: results from a Multicenter Kidney Transplant Consortium. Transplantation 91(3), 300-308 (2011).

70 Kniepeiss D, Renner W, Trummer O et al. The role of CYP3A5 genotypes in dose requirements of tacrolimus and everolimus after heart transplantation. Clin. Transplant. 25(1), 146-150 (2011).

71 Gijsen V, Mital S, van Schaik RH et al. Age and CYP3A5 genotype affect tacrolimus dosing requirements after transplant in pediatric heart recipients. J. Heart Lung Transplant. 30(12), 1352-1359 (2011).

72 Allison AC, Eugui EM. Purine metabolism and immunosuppressive effects of mycophenolate mofetil (MMF). Clin. Transplant. 10(1 Pt 2), 77-84 (1996).

73 Ohmann EL, Burckart GJ, Brooks MM et al. Genetic polymorphisms influence mycophenolate mofetil-related adverse events in pediatric heart transplant patients. J. Heart Lung Transplant. 29(5), 509-516 (2010).

74 Colobran R, Casamitjana N, Roman A et al. Copy number variation in the CCL $4 L$ gene is associated with susceptibility to acute rejection in lung transplantation. Genes Immun. 10(3), 254-259 (2009).

75 Li H, Xie HY, Zhou L et al. Copy number variation in CCL3L1 gene is associated with susceptibility to acute rejection in patients after liver transplantation. Clin. Transplant. 26(2), 314-321 (2011).

76 Sarwal MM, Benjamin J, Butte AJ, Davis MM, Wood K, Chapman J. Transplantomics and biomarkers in organ transplantation: a report from the first international conference. Transplantation 91(4), 379-382 (2011).

- Describes the emerging field of transplantomics.

7

Ebert MS, Sharp PA. Roles for microRNAs in conferring robustness to biological processes. Cell 149(3), 515-524 (2012).

78 Anglicheau D, Sharma VK, Ding R et al. MicroRNA expression profiles predictive of human renal allograft status. Proc. Natl Acad. Sci. USA 106(13), 5330-5335 (2009).

79 Kienzl-Wagner K, Pratschke J, Brandacher G. Proteomics - a blessing or a curse? Application of proteomics technology to transplant medicine. Transplantation 92(5), 499-509 (2011).

80 Freue GVC, Sasaki M, Meredith A et al. Proteomic signatures in plasma during early acute renal allograft rejection. Mol. Cell Proteomics. 9(9), 1954-1967 (2010).

81 Zhang Q, Reed EF. Non-MHC antigenic targets of the humoral immune response in transplantation. Curr. Opin. Immunol. 22(5), 682-688 (2010).

82 Reinsmoen NL, Lai CH, Heidecke $\mathrm{H}$ et al. Anti-angiotensin type 1 receptor antibodies associated with antibody mediated rejection in donor hla antibody negative patients. Transplantation 90(12), 1473-1477 (2010).

83 Li L, Wadia P, Chen R et al. Identifying compartment-specific non-HLA targets after renal transplantation by integrating transcriptome and "antibodyome" measures. Proc. Natl Acad. Sci. USA 106(11), 4148-4153 (2009).

\section{Websites}

101 A Comparison of AlloMap Molecular Testing and Traditional Biopsy-based Surveillance for Heart Transplant Rejection Early Posttransplantation (EIMAGE). http://clinicaltrials.gov/ct2/show/ NCT00962377

(Accessed 4 July 2012).

102 Wellcome Trust Case Control Consortium. Interactions between Donor and Recipient DNA that determine Early and Late Renal Transplant Dysfunction. www.wtccc.org.uk/ccc3/projects/ccc3_rtd. shtml

(Accessed 4 July 2012). 